\title{
Risco associado a movimento de massa no Morro Boa Vista (Vila Velha/ES): da caracterização do território à necessidade de políticas públicas
}

\author{
Risk associated with mass movement in the Boa Vista Hill \\ (Vila Velha/Espírito Santo): from territory characterization \\ to the need for public policies
}

\author{
Teresa Cristina da Silva Rosa ${ }^{[l]}$ \\ Marcelo Sathler ${ }^{[1]]}$ \\ Mirian Costa ${ }^{[\mathrm{III}]}$ \\ Marcos Barreto de Mendonça $a^{[\mathrm{IV}]}$ \\ Caterine Reginensi[ $\left.{ }^{[}\right]$ \\ Ricardo Matos de Souza ${ }^{[\mathrm{VI}]}$
}

\begin{abstract}
Resumo
Este artigo busca compreender o processo de vulnerabilização de uma comunidade situada no Morro Boa Vista (MBV, Vila Velha, ES) numa perspectiva interdisciplinar, utilizando-se de questionário para levantar aspectos da percepção do risco, de entrevistas para resgatar a história da ocupação, de registros fotográficos e de análise da geologia local. Evidencia-se uma ocupação influenciada por forças políticas que impeliram a população ao local, iniciada nos anos 1960, subsequente ao êxodo rural concomitante à industrialização do Espírito Santo. Em janeiro de 2016, por ausência ou omissão do poder público, um desastre no local em função de rolamento de rochas desvelou esse processo e a condição de subcidadania dos seus moradores, evidenciando a urgência de medidas de redução de risco de desastres.
\end{abstract}

Palavras-chave: redução de risco de desastre (RRD); rolamento de rochas; ocupação do solo urbano; desastre; Vila Velha (ES).

\begin{abstract}
This article aims to understand the vulnerabilization process of a community located on the Boa Vista Hill (city of Vila Velha - State of Espírito Santo) from an interdisciplinary perspective. Methods included a risk perception survey, interviews to collect the history of the occupation, photographic records and local geologic assessment. The scenario shows an occupation influenced by political forces that impelled the population to occupy the area in the 1960s, after the rural exodus that occurred simultaneously to the State's industrialization. Either by the absence or omission of the public authorities, the rockfall disaster of January 2016 exposed that process, as well as the second-class citizenship of the local population and the urge for measures to reduce the risk of disasters.
\end{abstract}

Keywords: disaster risk reduction (DRR); rockfall; urban soil occupation; disaster; Vila Velha (ES). 


\section{Introdução}

As cidades brasileiras têm o uso e a ocupação desorganizados do solo como característica. A ausência de ordenamento ou a sua inadequação à realidade urbana favorecem ao aumento de risco de desastres nas áreas urbanas, pois uma das consequências do uso do espaço nessas condições é a ocupação de áreas de risco passíveis de desastres futuros (Maricato, 1996, p. 58). Compreende-se como risco a combinação de fatores que aumentem a probabilidade de um evento danoso a vidas humanas, ao patrimônio e ao meio ambiente (UNISDR, 2009). Assim, a característica das cidades brasileiras, que ocupam desordenadamente o solo urbano (Maricato, 1996), conjugada ao uso sem o reconhecimento à lógica ecológica do local ( $\mathrm{Da}$ Silva Rosa et al., 2016) emergem como fatores que parecem justificar o aumento de desastres em ambiente urbano no Brasil nos últimos anos (Ceped/UFSC, 2013; CPRM, 2012).

As cidades no Espírito Santo (ES) e, especialmente, a Região Metropolitana da Grande Vitória - RMGV, podem ser apontadas como exemplo dessa premissa. Devido às atividades econômicas do Brasil no período colonial e a fragilidade político-militar da colônia e do império português, o ES teve seu desenvolvimento urbano tardio em relação aos estados vizinhos da região Sudeste (Oliveira, 2008, p. 457). Este ocorreu, no início dos anos 20, ganhando mais impulso nos anos 60/70 (Siqueira, 2001, p. 131; Mattos, 2011, p. 105) por conta da implantação de grandes projetos de desenvolvimento e de empreendimentos imobiliários, basicamente nos anos 90, como reflexo de dois períodos de internacionalização da economia do ES. Pode-se afirmar ter sido um crescimento bastante acelerado, produzindo cidades de difícil gestão, principalmente, em relação aos desastres em razão de sobreposição de vulnerabilidades sociais e ambientais (CPRM, 2017; da Silva Rosa et al., 2018).

Situado na RMGV, o município de Vila Velha (VV) ilustra a complexidade da vulnerabilidade socioambiental. Ele teve sua urbanização, majoritariamente, ocorrida no contexto de modernidade, em que a ocupação do solo urbano ocorre como se fosse um espaço "vazio" aguardando um projeto de desenvolvimento e de urbanização que ignora as características biogeofísicas presentes (da Silva Rosa et al., 2016). Separada da capital do estado, Vitória, pela Baía de Vitória, VV é conurbada, à oeste, com o município de Cariacica, constituindo com esses e os municípios de Serra, Guarapari, Viana e Fundão, a RMGV. 0 município de VV é dotado de elevações rochosas às margens da Baía, entre estas e o Morro do Boa Vista (MBV), localizado no bairro São Torquato, que compõe, geologicamente, a suíte intrusiva do Espírito Santo, parte do Maciço Vitória (Vieira e Menezes, 2015), formado por rocha ígnea, granito.

No Morro do Boa Vista, tal como a urbanização predominante desse município, sua ocupação foi, inicialmente, "espontânea", o que se desvela nos tipos de construções observadas no local, características de aglomerados subnormais. Essa ocupação teve maior intensidade concomitantemente ao início da operação de grandes projetos industriais instalados ao redor da capital, responsáveis por atrair migrantes para a atual metrópole e promover muito da sua configuração atual (Siqueira, 2001, p. 145; Celante, Sathler e da Silva Rosa, 2015). Na sua maioria, as residências concentram-se na face sul do morro em 
terreno íngreme repleto de matacões e sujeito à rolamentos (CPRM, 2012; Big All, 2016; Defesa Civil Estadual do ES, 2016). Em $1^{\circ}$ de janeiro de 2016, um evento na comunidade veio a confirmar essa suscetibilidade da área aos movimentos de massa: parte de uma rocha localizada no seu cume rompeu-se, ocasionando o rolamento de um de seu fragmento de rocha, que obliterou tudo em seu percurso.

Considerando esse contexto, a proposta deste artigo é de compreender o processo de vulnerabilização dessa comunidade situada na encosta do Morro Boa Vista, buscando discutir possíveis fatores contribuintes para o risco, incluindo aspectos da percepção de risco. Pressupõe, assim, que a vulnerabilização é multifatorial e que o risco evolui em função de alterações no ambiente (Gamboa, 2008; Douglas e Wildavsky, 2012). Para tal, procura-se o conhecimento de diferentes disciplinas no sentido de melhor compreender esse cenário de vulnerabilização no recorte de redução de riscos de desastres (RDD). Além disso, os estudos de percepção de risco focam os julgamentos das pessoas quando arguidas sobre a caracterização e avaliação das ameaças às quais estão relacionadas, possibilitando, assim, entender e prever suas relações e atitudes diante delas, de modo melhorar a comunicação sobre os riscos entre os diferentes atores sociais (Slovic, 1987). Isso significa assumir que a dimensão social e cultural é inerente à percepção de risco (Douglas e Wildavsky, 2012).

Assim, compreende-se que essa abordagem implica trazer para a discussão o processo de urbanização da referida região, numa perspectiva histórica, além de evidenciar as condições geológicas locais e de entender o processo de formação da cidadania de seus habitantes em tais circunstâncias. Procura-se, portanto, combinar simultaneamente a abordagem dos aspectos físicos com a dos aspectos sociais, posto que o risco de desastre emerge de uma complexa relação entre os sistemas humano e natural (Malamud e Petley, 2009).

Como forma de atingir os objetivos acima, optou-se por realizar os seguintes procedimentos metodológicos: 1) observação em campo por equipe multidisciplinar logo após o evento; 2) aplicação de questionário semiestruturado a 18 moradores de famílias distintas impactadas, direta ou indiretamente, pelo rolamento das rochas. Esse questionário, composto de 15 perguntas, levantou as condições e o uso dos imóveis e buscou atentar para aspectos da percepção de risco; 3) levantamento do histórico de formação da comunidade através de entrevistas não estruturadas com os moradores mais antigos do MBV, cujas histórias de vida confundem-se com a história da ocupação da área; e 4) levantamento de dados sobre a geologia e tectônica regionais em busca de fatores capazes de terem contribuído com o desastre.

0 presente trabalho está organizado em quatro partes. Primeiro, descrevem-se o desastre e a relação do poder público com essa situação. Em seguida, apresenta-se uma análise dos fatores geológicos que, possivelmente, estão relacionados ao evento. Na terceira parte, contextualizam-se a comunidade em questão e a percepção da população quanto ao risco. $\mathrm{Na}$ quarta parte, discorre-se sobre a história da formação da comunidade e do processo de construção do risco. Finalmente, discute-se sobre o não reconhecimento dessa população e o seu necessário empoderamento, inclusive de acesso aos direitos estabelecidos constitucionalmente e sobre como o poder público poderia 
desenvolver políticas públicas voltadas para 0 direito fundamental à moradia, enquanto direito social.

\section{0 desastre do Morro de Boa Vista: uma tragédia anunciada?}

Ao final de uma tarde ensolarada do $1^{\circ}$ dia do ano de 2016 e durante um extenso período de estiagem, ${ }^{1}$ parte de uma rocha presente no cume do MBV desprendeu-se, colocando em movimento um fragmento de cerca de 3000 toneladas que atingiu a comunidade local. Esse bloco de rocha destruiu quatro casas e feriu quatro pessoas, e outras 10 socorridas pelos moradores, tendo uma ação de assistência do Corpo dos Bombeiros (Defesa Civil Estadual do ES, 2016; Falcão, 2016; Rezende, 2016). Os moradores presentes em suas residências relataram ter escutado um grande tremor e um barulho assustador houve quem, a princípio, achou tratar-se da explosão de uma bomba (da Silva Rosa et al., 2018) ou, ainda, da queda de um avião.

As observações feitas no local revelam um uso do território com características da modernidade tardia, segundo as quais a ocupação se deu pela população de baixa renda e baixa escolaridade em edificações de baixo padrão construtivo e sem planejamento num espaço considerado de menor valor imobiliário (Defesa Civil Estadual do ES, 2016; da Silva Rosa et al., 2018). No seu trajeto, o fragmento de rocha chocou-se com e movimentou diversas outras rochas menores. A situação local então foi determinante para que o Corpo de Bombeiros e a Defesa Civil evacuassem da área à jusante de onde o bloco parou, considerando o risco iminente de um segundo rolamento de blocos, alojando parte dos moradores em uma escola municipal próxima ao local. Segundo o CPRM (2012), toda a comunidade estava em situação de risco. Em janeiro de 2012, o Serviço Geológico Brasileiro (SGB) reconheceu dezesseis áreas consideradas de alto ou muito alto risco no MBV, recomendando a remoção imediata dos moradores mais próximos ao topo do morro, o que envolvia, aproximadamente, 400 casas e 2000 pessoas (CPRM, 2012).

Pressionada por essa recomendação e pela destruição de uma casa pelo rolamento de um outro bloco de rocha em agosto de 2012, a Defesa Civil realizou, em novembro desse ano, uma simulação, com a comunidade, de situação de chuva intensa diante de agravamento do risco. Constituiu-se num treinamento de evacuação que envolveu 54 famílias e 200 pessoas (Valfré, 2012), moradoras do entorno da casa atingida em 2012. Em novembro de 2013, o município, através da Defesa Civil, criou o Plano de Contingência de Vila Velha, com o intuito de ordenar "ações de prevenção, preparação e resposta para a minimização de efeitos de desastres e restabelecer a normalidade social", destacando a situação do MBV como de alta prioridade (Defesa Civil de Vila Velha, 2013). Contudo, alegando falta de recursos, a PMVV não removeu os moradores e tão pouco realizou ações não estruturantes, como a literatura de redução de risco de desastre (RRD) recomendava (Sousa, 2015; Mendonça et al., 2015). Após o desastre de janeiro de 2016, a Defesa Civil estadual e uma consultoria independente produziram laudos distintos. Ambos corroboraram o trabalho da SGB, constatando 
mecanismos deflagradores de processos geológicos naturais resultantes da alta declividade, do solo raso e da abundância de matacões aflorados (Big All, 2016; Defesa Civil Estadual do ES, 2016). 0 trabalho da consultoria ainda categorizou parte do solo da vertente ocupada como depósito de tálus, tipo de solo resultante de movimento de massas, incluindo blocos da rocha (Big All, 2016), característica que reforça a suscetibilidade do local a esses eventos. Em seu laudo, a Defesa Civil destacou a movimentação de outros blocos graníticos menores pela passagem do fragmento desprendido do topo e a necessidade imediata de contenção de toda a massa existente ao longo do percurso devastado de maneira a ser evitada uma segunda tragédia. Ou seja, o risco de movimento de massa ainda persistia no local (Defesa Civil Estadual do ES, 2016).

\section{A base biogeofísica do território: elemento da evolução de paisagem}

A movimentação de blocos de rocha constitui um processo natural de evolução da paisagem; proporciona, no entanto, risco maior quando em meio à ocupação humana ou à urbanização realizada sem os devidos critérios técnicos. Essa movimentação envolve processos físicos de natureza geotectônica e climática (Grotzinger e Jordan, 2013, p. 174) e é acentuada por fatores como a presença de lascas, o grau de fraturamento e a declividade (Guidicini e Nieble, 1976, p. 69). Com base em observação do local do desastre e considerando casos anteriores, podem ser identificados, a princípio, cinco fatores geológicos, que, correlacionados, podem ter contribuído para o desprendimento do bloco de rocha: 1) litologia; 2) estrutural; tectônica, constituindo eventos; 3) sísmicos naturais; 4) sísmicos induzidos por atividades antrópicas; e 5) fator climático.

0 estudo se insere na área Tropical Atlântica brasileira e no domínio paisagístico morfoclimático que Ab'Saber (2003, p. 57) define como sendo o "Domínio Mares de Morros". Tal domínio caracteriza-se por estar sujeito aos mais fortes processos gravitacionais de movimentos de solos do País. Segundo esse mesmo autor, as características geológicas e topográficas intrínsecas de cada unidade do Domínio Mares de Morros possuem questões problemáticas diante da ação antrópica que é intensa na faixa atlântica do País. No caso do $M B V$, com base nas observações feitas até 0 momento, essa situação é agravada pela inclinação do talude, alcançando em torno de $80 \%$ de declividade na parte mais escarpada, ou seja, quase verticalizado.

0 relevo composto por rochas graníticas é comum na região Sudeste do Brasil. A geologia do município de VV ainda é tema de estudos e discussões científicas, carente, portanto, de levantamentos geológicos, geotécnicos e geofísicos em escala de maior detalhe. Porém, através do levantamento bibliográfico realizado para este estudo, foi possível identificar que o MBV é constituído, basicamente, por rochas de composição granítica; textura média; coloração cinza; com megacristais de feldspatos (Vieira e Menezes, 2015). ${ }^{2}$

A caracterização litológica é fundamental para o entendimento dos processos de evolução da paisagem, pois a composição da rocha reflete o grau de suscetibilidade aos processos 
intempéricos e tectônicos (Grotzinger e Jordan, 2013). Apesar de essas rochas serem constituídas, em sua maioria, por minerais resistentes ao intemperismo, como o quartzo, o clima tropical típico da área de estudo pode provocar intensa alteração química de minerais menos resistentes, amplificando a possibilidade de movimentação de blocos (ibid., p. 174). A concentração pluviométrica aliada à alta declividade são notórias agravadoras dos movimentos de massa (Guidicini e Nieble, 1976).

Apesar de ser uma região com considerável precipitação anual, principalmente nos meses de novembro e dezembro, com médias de 214,2 mm/mês desde 1976 (Incaper, 2017), os dois últimos anos anteriores ao desastre apresentaram médias de 95,8 mm/mês em 2014 e $67,2 \mathrm{~mm} / \mathrm{mês}$ em 2015 , contra os 221,58 de média mensal para dezembro desde 1976 (ibid.). Quanto à temperatura, foi observado um aumento mínimo de $1^{\circ} \mathrm{C}$ nos meses de novembro e dezembro, entre os anos de 2014 e 2015; e, em dezembro de 2015, a temperatura média foi de $27,5^{\circ} \mathrm{C}$, quando a média, observada desde 1976 , é de $25,8{ }^{\circ} \mathrm{C}$, conforme 0 Incaper (ibid.).

A ação do clima associada à presença e ao padrão de fraturamento e/ou esfoliação esferoidal dos maciços graníticos condicionam os processos de queda de blocos. As fraturas, juntas ou falhas consistem em planos de fraqueza contínuos e persistentes, que permitem a percolação da água e o aparecimento de subpressões, além de favorecer o intemperismo químico ao longo das superfícies. 0 fraturamento rochoso pode ser associado a processos de natureza tectônica compressiva e distensiva, ocorridos ao longo da história geológica dos maciços da região Sudeste (Saadi, 1993).
Esses processos somados ao desenvolvimento de raízes de árvores reduzem o grau de fixação da massa rochosa, possibilitando o movimento gravitacional de blocos (Pinotti, 2010). Já a dilatação térmica causada pela a oscilação de temperatura pode resultar em um fator preponderante na geração e intensificação de descontinuidades nos maciços (Lima, 2002), principalmente em ambientes com alta oscilação térmica e diminuição da pluviosidade, como ocorreu entre 2014 e 2015.

Os afloramentos do MBV ocorrem intensamente fraturados, com fraturas de orientação, preferencialmente, Leste-Oeste (Figura 1). 0 fraturamento associado às condições climáticas que antecederam ao desastre foi correlacionado à causa do movimento de massa por vários órgãos em seus pareceres, como a Defesa Civil estadual. No entanto, essa interpretação não é conclusiva devido à falta de estudos mais detalhados e, também, à abordagem do requisito tectônico, constituído de eventos sísmicos naturais ou induzidos por atividades antrópicas, além do requisito ocupação humana.

No requisito tectônico, a borda leste da plataforma Sul-Americana é, geralmente, considerada uma região geológica estável, não estando sujeita a grandes abalos sísmicos. No entanto, na região Sudeste do Brasil, foram relatados diversos abalos sísmicos de baixa magnitude, sentidos apenas através da oscilação em altos edifícios (Assumpção et al., 1997). Atualmente, esses abalos são correlacionados a esforços intraplaca, em consequência da reativação de zonas de fraquezas pela tectônica global (Lima, 2002). Esse requisito é um dos mais difíceis de ser mensurado no atual momento devido à complexidade de fatores geológicos envolvidos e à falta de informações em 
Figura 1 - Área do rolamento de bloco

e o antes e o depois do despreendimento

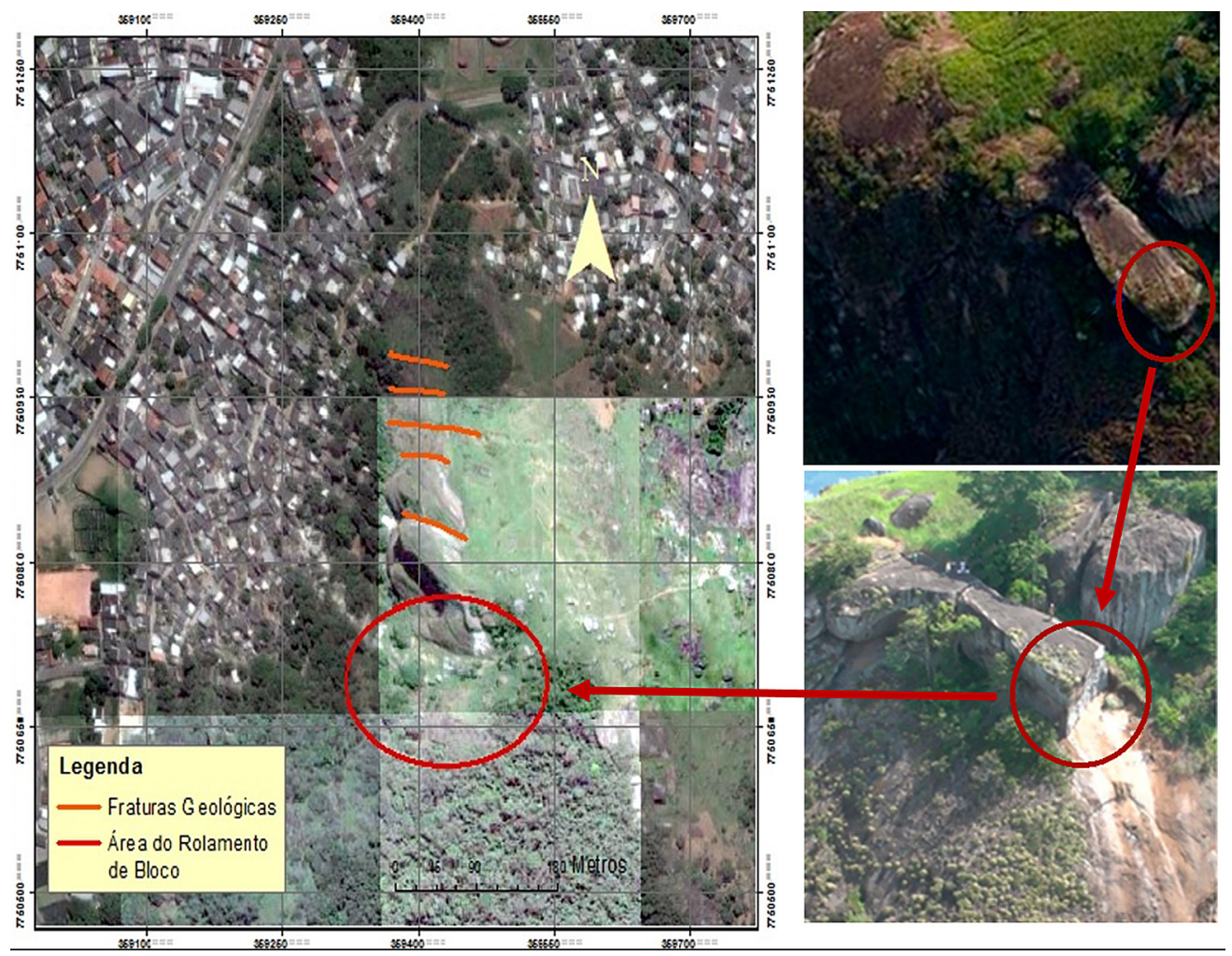

Fonte: mapa elaborado pelos autores e fotos da Prefeitura de Vila Velha.

escala de detalhe. Por isso, relacionar os eventos de quedas de blocos a sismos originados da reativação tectônica de antigas zonas de falha não é uma tarefa fácil, apesar de notória em algumas regiões do País.

Todavia, os sismos ou terremotos podem ser também gerados a partir de atividades antrópicas, como a atividade sísmica causada pelo desmonte de rochas e/ou para estudos exploratórios, por exemplo, relacionadas à atividade mineradora. Essa atividade pode gerar abalos sísmicos de ordens de grandeza variáveis, dependendo da quantidade de explosivos utilizados e das características do meio, no qual as ondas sísmicas estarão se propagando (Assumpção et al., 2002).

Ao norte do MBV, encontra-se a Baía de Vitória onde a obra de derrocagem do porto de Vitória foi licenciada com o uso de explosivo para o aprofundamento do seu canal, segundo o Relatório Especial "Monitoramento Sísmico da Obra de Derrocagem na Baía de Vitória" 
(2012), apresentado ao Instituto Estadual de Meio Ambiente do estado do Espírito Santo (lema). Conforme esse relatório, a atividade sísmica foi planejada e executada seguindo as normas preconizadas pela a NBR-9653. A literatura é clara em afirmar que, em casos similares, devem ser considerados vários fatores de propagação das ondas nos diferentes meios, como, no caso, a presença de fraturas, falhas, heterogeneidade litológica e fatores antrópicos, como a presença de residências com estruturas precárias. Entretanto, embora a apenas cerca de 1,5 km do local das explosões, 0 MBV não foi inserido nem na área de interferência direta, nem indireta desse empreendimento, descartando-o dos estudos de impactos socioambientais da atividade de derrocagem. Além disso, tais explosões parecem fazer parte do imaginário da população, visto que alguns relatos apontam "estrondos e explosões" como motivo do deslizamento da rocha, conforme mostrado a seguir (da Silva Rosa et al., 2018).

A não inserção do MBV, assim como de outras áreas da região do entorno, nos estudos socioambientais de licenciamento, dificulta a análise do papel dessa atividade diante do desastre porque não houve qualquer monitoramento quando do uso de explosivos e consequente propagação de ondas.

\section{No "caminho" da pedra, a comunidade do MBV}

A comunidade em risco é composta, majoritariamente, por moradores recebendo até $1 / 2$ salário mínimo por mês, e a maioria de suas edificações são de casas multifamiliares dotadas de dois ou mais pavimentos, em alguns casos com comércio conjugado, dedicados à alimentação ou ao lazer, como bares, por exemplo (ibid.). A partir do trabalho de campo feito em períodos pós-desastres, destacaram-se, ainda, as edificações ocupadas por templos religiosos de diversas denominações, porém sem diferenciação arquitetônica das demais construções, salvo raras exceções. Nesse aglomerado subnormal, são poucas as vias pela qual é possível a circulação de veículos. Em geral, elas foram mantidas ou abertas pelos próprios moradores e pavimentadas com materiais de naturezas distintas e de maneira irregular. 0 asfalto, mal-acabado, é presente somente onde há a circulação de veículos, não ocorrendo a entrada de transporte coletivo.

Portanto, o serviço público é de baixa qualidade, o que acentua a vulnerabilidade socioambiental dessa comunidade; além disso, ela é mal-iluminada, agravando a sensação de insegurança (ibid.). Há discretos, porém presentes, vazamentos de água tratada e de esgoto, não sendo possível, entretanto, mensurar se a infiltração desses líquidos contribuiria significativamente para o aumento de instabilidade dos taludes.

Durante o período de trabalho de campo, foi observada a existência de narcotraficantes, o que foi confirmado através de testemunhos relatando confrontos entre facções rivais, o que dificulta, em alguns momentos, a circulação dos pesquisadores. No período do pós-desastres, 0 Estado estava atuando localmente, quando teria havido uma "trégua" para que os trabalhos do poder público pudessem ser efetivados.

Quanto à percepção de risco referente ao evento, foram entrevistados 18 ( $n$ ) membros de famílias distintas, entre eles dois moradores da área evacuada. Desses 18 entrevistados, 
$66,7 \%$ eram do sexo feminino, $87,6 \%$ com idade superior a 21 anos e $66,6 \%$ moradores de residências unifamiliares com até seis pessoas. Os entrevistados tinham acesso à água tratada, porém apenas 38,8\% tinham acesso ao esgotamento sanitário. 0 imposto sobre a propriedade dos imóveis ${ }^{4}$ é cobrado de 33,3\% dos respondentes, ${ }^{5}$ dado que em conjunto com os restantes indicam condições de vulnerabilidade socioeconômica de $66,7 \%$ das famílias entrevistadas (ibid.).

Durante o rolamento de blocos, $61 \%$ dos entrevistados estava na comunidade, seja na casa de vizinhos ou nas suas próprias casas. Destes, $17 \%$ disseram ter escutado estrondos e explosões oriundos do desprendimento da rocha; $54,5 \%$ relataram ter recebido auxílio imediato de vizinhos ou da associação de moradores; 27,3\% tiveram auxílio da Defesa Civil - não ficou claro se é a municipal ou a estadual. Daqueles $61 \%$, a metade se disse insatisfeita com o poder público, em geral, e com as ações daquele órgão, que exigiu o deslocamento temporário de $83,3 \%$ dos amostrados; destes 38,8\% abrigaram-se, temporariamente, na escola do bairro mais próxima do evento e os demais em casas de vizinhos, parentes ou amigos. Do total de deslocados, $16,6 \%$ tiveram suas casas impactadas de alguma forma ou comprometidas pelo evento. Quanto às possíveis razões para o evento apontadas pelos entrevistados em pergunta aberta, destacam-se duas categorias de respostas: causas naturais (44\%) e o desconhecimento de possíveis razões $(22 \%)^{6}$ (ibid.).

A insatisfação registrada acima se deve, provavelmente, às poucas ações de preparação da população para lidar com um evento; e de precaução por parte do poder público. No caso ocorrido, há o imprevisto do evento, que poderia ter sido monitorado, posto que a área havia: (1) sofrido com um evento em 2012; e (2) sido identificada, no Plano de Contingência de VV (2013), como de risco muito alto e com indicação de necessidade de remoção dos moradores e obras de contenção. Mesmo sem atender às essas indicações, foi realizada uma única ação não estrutural de simulação (em 2012), contudo, para a situação de chuva intensa, que não foi o caso presente.

A solidariedade entre os vizinhos pode ser vista como uma estratégia espontânea de adaptação, criada, pelos próprios moradores, com base em laços comunitários históricos (vide os mutirões relatados aqui mais à frente), ou seja, independentemente de qualquer ação pública. Essa omissão do poder público na fase de preparação, negligenciando a exposição ao risco da população, é um fator contribuinte para que a população se sinta distante dos ou não reconhecida pelos órgãos públicos, fato observado em outros estudos de percepção de risco, como no caso relatado por Mendonça e Gullo (2012).

Cabe esclarecer que as respostas podem ter sido influenciadas pela mídia local, visto que a aplicação do questionário ocorreu enquanto ela apontava os processos naturais como responsáveis pelo evento, embora as análises técnicas não tivessem sido, ainda, concluídas naquele momento (ibid.). A justificativa para o rolamento ter sido provocado por "bomba ou tiroteio" pode estar, possivelmente, ligada à suposta disputa de território local por narcotraficantes rivais; ou, no caso de bomba, que os abalos possam estar relacionados às obras de derrocagem para o aumento de calado da Baía de Vitória. 


\section{0 processo de ocupação e de construção do risco}

O estado do Espírito Santo teve seu desenvolvimento tardiamente em relação a outras áreas do País provavelmente devido ao seu papel no histórico do processo de expansão do Brasil - colônia do litoral para o interior do País. As descobertas minerais (ouro e prata) na área que corresponde hoje ao estado de Minas Gerais resultaram em proibição de benfeitorias e estradas, de modo a formar uma barreira evitando os desvios de ouro e a entrada de saqueadores pelo litoral capixaba (Oliveira, 2008). Esquecido, política e economicamente ao longo do tempo, o Espírito Santo manteve a sua estrutura rural até a metade do século XX com uma pequena população (Almeida e Gomes, 1985; Santos, 1999; Almeida, 2010). É nesse contexto que Vila Velha cresce sob o impulso de uma economia em transição entre o rural e o urbano-industrial, tendo uma urbanização que se caracterizou por ser desordenada e ligada ao duplo processo de nacionalização e internacionalização econômica do ES.

Nos últimos anos, Vila Velha ganhou destaque na mídia nacional a cada período de chuvas por sua suscetibilidade a eventos hidrometereológicos extremos. Idealizada a partir de uma racionalidade desrespeitosa à lógica da sua base biogeofísica, a cidade litorânea formou-se impermeabilizando regiões de baixa cota altimétrica durante um processo de extração de solo arenoso para a edificação da cidade moderna sob o impacto da especulação imobiliária. Todo esse uso e ocupação do solo diminuíram ainda mais sua cota em relação ao mar, tornando-a refém das marés e das chuvas, que, quando em sinergia de abundância, condenam sua drenagem e a alagam (Sathler et al., 2016).

Um dos primeiros bairros em Vila Velha, São Torquato foi ocupado por estar situado na margem da Baía oposta ao centro de Vitória, onde, historicamente, aglomerava-se a vida política e comercial do estado (Celante et al., 2015). Assim como em toda Vila Velha, a ocupação inicial desse bairro se focou, naturalmente, nas áreas não sujeitas aos alagamentos e às inundações e não demandantes de aterro para construção de moradia. Logo, os terrenos tornaram-se economicamente inacessíveis à população que migrou para buscar emprego na "cidade", principalmente, após as décadas de 1960/1970 (Siqueira, 2010). Por seguinte, MBV tornou-se uma opção para a população sem acesso aos raros programas habitacionais - os subcidadãos como será visto adiante - ainda que muitas fossem as suas dificuldades, pois o perfil de subsolo do local é praticamente desprovido de camadas espessas de solo. Mesmo aqueles que, porventura, intentassem se apropriar de áreas públicas ou não ocupadas sofreriam, além da tentativa de serem retirados dos locais ocupados, com a hidrologia local.

Com o intuito de contribuir para o meIhor entendimento desse processo de ocupação, lança-se mão de relatos de recordadores, os moradores mais antigos da área de estudo (a ocupação inicial). No início da sua ocupação, a subida do morro exigia certa atenção em razão do risco de acidentes pela presença de matacões (típicos dessas elevações) e de grandes blocos de rochas e, principalmente, pelas diversas fissuras profundas nas rochas que formavam o chão. Os ocupantes eram obrigados 
a darem saltos sobre elas para chegarem a pontos mais altos, tal como no relato dessa imigrante de ancestrais italianos, oriunda de zona rural do estado, à época, pertencente ao município de Santa Teresa/ES, hoje, município de São Roque do Canaã:

Cheguei aqui em 16 de fevereiro de 1960. Foi "anteontem". Quando eu cheguei aqui só tinha uns cinco barracos simples cobertos de palha, mais ou menos isso. Aqui tinha lugar de pisar, de pular de uma pedra para outra para poder andar. Ali era um pasto, restava umas capoeiras. Eu não morava aqui, não. A gente morou num barracão de madeira só com um "comodozinho", bem lá em cima. Do lado de fora [do cômodo] tinha um puxadinho com fogãozinho à lenha. Éramos quase os últimos ${ }^{7}$ moradores. Aí meu marido comprou um pedacinho de terra bem aqui onde estamos. Já tinha gente que tinha marcado a terra. A gente comprava baratinho. Compramos aquis por 17 cruzados. Fizemos um barraquinho de tábua, capa de caixote, zinco, daí ganhamos as telhas e fizemos um negócio mais direitinho. (Sra. DL.)

0 relato acima rememora as características biogeofísicas, a presença de matacões que tornavam a superfície bastante acidentada e a movimentação arriscada, uma área de certa complexidade que foi ocupada com pouca ou nenhuma infraestrutura, conforme complementado pelo testemunho que acrescenta mais informação sobre as condições de vida na comunidade no início da ocupação do MBV:

Fui nascida e criada aqui. Tenho 70 anos. Minha família é de Vitória mesmo, só não sei o lado [local de origem]. Aqui tinha umas quatro ou cinco casas de tábua quando eu era criança. As pessoas mais antigas morreram quase tudo. Pegávamos água num poço aqui, muito antigo. Aqui em cima não tinha nascente. Depois a gente pegava água no Beco da Água. A gente pegava lenha sabe aonde? Nas tamancarias. ${ }^{9}$ Lá em Paul, Jardim América, de primeira. Quase não tinha lenha aqui no morro, [quando tinha] a gente pegava lá em cima [nas áreas mais altas do morro]. Fazíamos feixe de lenha e trazia na cabeça. Nossa vida era essa... não tinha luz, não, só lá embaixo. Era na lamparina. (Dona N.)

Com base no relato acima, vale ressaltar a presença de nascentes, outra característica dos maciços rochosos em VV, bem como as raras vegetações que dão lenha, obrigando os moradores a se deslocarem para bairros vizinhos em busca de lenha. 0 sr. J. B., que se considera membro da sexta família a habitar o $M B V$, relatou ainda:

Cheguei aqui com 6 anos de idade, em 1959. Aqui no Morro só tinha [sic] seis casas. Tudo barracão. Barracão lá em cima, barracão lá embaixo. Tinha o centro de macumba da dona Maria. Foi chegando um, foi chegando outro. Era um matagal danado. Pegava água lá no Beco da Torneira. Tinha uma dona que morava ali do outro lado do morro que pegava água do cano mestre ${ }^{10}$ do Cobi e que deixava eu pegar água lá porque eu namorava uma sobrinha dela. Mas a água só chegava de madrugava, antes não tinha água, não. Tinha uma água ${ }^{11}$ numa matinha lá em cima, sim. [...] Em 1966 tinha [sic] poucas casas aqui. Ali embaixo tinha a linha do trem, o resto era um brejo danado. Em volta, até 1969, eu me lembro bem, não tinha quase nada ali embaixo.

Chama a atenção tanto o pequeno número de moradias nesse período de fim dos 
anos 1950 e início dos 1960, marcando o começo dessa ocupação por pessoas de origem rural e urbana, como as dificuldades dessa ocupação, conjugando as poucas posses com o raro acesso à infraestrutura e as características locais - nascentes, matacões, capoeiras, pouca lenha, na parte baixa o brejo (típico da geografia de VV) e a linha do trem. Observando as datas de chegada nos testemunhos acima bem como em outros relatos feitos, constata-se que a ocupação coincide com 0 período de implantação dos grandes projetos de desenvolvimento na Região Metropolitana da Grande Vitória. Isso reforça a ideia de que tais empreendimentos causaram o primeiro movimento coletivo de ocupação do MBV, bem como o de VV.

A partir desses relatos, pode-se inferir que essa ocupação ocorre num ambiente onde as características naturais originais já estavam degradadas. 0 pasto e a capoeira citados levam a pensar que as árvores nativas foram, anteriormente, retiradas, possivelmente, para construção de casas, de utensílios e ou de produção de energia. Parece ter ocorrido um uso extensivo dos recursos naturais locais, causando o repovoamento com vegetação típica de capoeira, que se caracteriza por ser uma vegetação de estágio inicial da sucessão ecológica (Catharino, 1989). Aos poucos, podem ter sido introduzidos, nas áreas de solo, capinzais e plantas frutíferas, como hoje se pode, facilmente, ver mangueiras e jaqueiras, visivelmente plantadas pelos moradores, seguidas de bananeiras e pés de acerolas e pitangas; além das ornamentais, como as populares palmeira-areca (Dypsis lutescens) e a espada de são jorge (Sansevieria trifasciata). Há, também, a presença de leucena (Leucaena leucocephala), espécie exótica com grande potencial de propagação, presente em toda Vila Velha.

Ainda, com base na descrição de suas moradias na época em que foram ocupar o morro, fica claro que os primeiros habitantes do MBV eram, possivelmente, pessoas de pouquíssimas posses. Assim como a dona N. relata que sua família veio de Vitória, Silva (2015)، em seu texto, afirma que muitos bairros populares de Vila Velha cresceram sob a influência de população vinda de Vitória porque, segundo esse autor, havia um projeto modernista em Vitória de valorização da capital, no qual não caberiam as "classes desfavorecidas" (ibid., p. 139). Em paralelo, o que a literatura sobre a ocupação de Vila Velha deixa antever é que há, também, uma ocupação de origem rural, com aqueles que vieram do norte do ES (Celante et al., 2015). Assim, o processo de ocupação do MBV se insere nessa dinâmica migratória tanto vinda de Vitória, com seu projeto modernista excludente, quanto de áreas rurais em crise econômica, decorrente da política de Estado de erradicação do café. Essa questão no campo pôde ser observada em alguns relatos, como é o caso abaixo do sr. F, ex-morador do córrego Santa Júlia, local de origem de DL:

Era uma seca [na zona rural]. Uma tristeza. Casei em 1968. o plantio de 1968 deu uma mixaria. Quase nada de milho e feijão. 0 meu pai já tinha se mudado pra cá [Vila Velha]. Em 1969, perdemos tudo! Plantamos $60 \mathrm{~kg}$ de milho, muita coisa. Eu e minha esposa sozinhos. Um trecho, só, pequeno de terra arado com boi, o resto foi tudo na enxada. Deu um matagal bonito ${ }^{12}$... o sol de janeiro acabou com tudo. Às vezes $3 h / 4 h$ para achar quase nada. ${ }^{13}$ Tivemos que tratar as "criação" com cana, banana e mamão. No ano seguinte, 
a mesma coisa. Só no outro ano que foi dar coisa, deu muito. Eu era meeiro e tive que sair de onde estava, a terra foi vendida. 0 meu pai tinha vindo em 1968, cansado daquela dificuldade, já trabalhava na Ferro\& Aço. ${ }^{14}$ Sabia que se eu fosse para outro lugar, iria acabar "formando"15 a terra e logo teria que sair. Resolvi vir. Veio tanta gente que um terreno de 50 cruzeiros, em 1968, valia 1000 ou 1500 cruzeiros, em 1972, e faltava transporte para mudança de quem queria vir.

Observa-se, no testemunho acima, que a vinda para a "capital" não significou uma mudança radical nas condições de vida. Tal como nos relatos anteriores, as condições de habitação precárias acabaram tornando-se um ambiente insalubre. Visto que os primeiros moradores não tinham acesso às redes públicas de água e esgoto, buscando água no poço utilizado no início da ocupação, rapidamente abandonado à medida que os moradores instalavam fossas sépticas, ou em uma torneira pública fornecida gratuitamente pela companhia municipal de abastecimento de água fora do morro em área adjacente a ele, no chamado Beco da Água. Esta era coletada em latões e levada morro acima a pé sobre as rochas nuas, sem auxílio de escadas ou corrimões durante o trajeto. A Figura 2 mostra crianças carregando água para os eventuais mutirões em prol da melhoria da comunidade e revela algumas características do local. A rua sem calçamento, mas, possivelmente, com energia elétrica e água encanada, visto o poste fixado ao solo à direita da imagem e o encanamento ao longo das cercas das moradias ou cruzando o caminho. 0 único registro fotográfico de um mutirão (à direita), possível de recuperação, foi 0 da construção da primeira igreja católica local, contudo sem data exata.

Figura 2 - Crianças auxiliando mutirão no MBV e Mutirão para construção de igreja
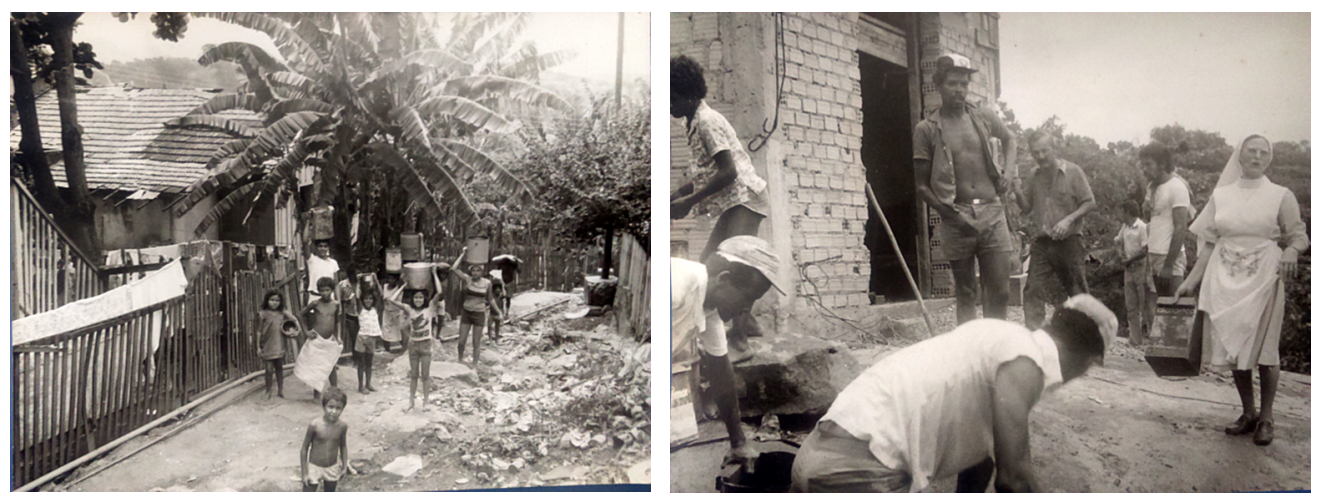

Fonte: acervo dona DL. 
Mesmo assim, os relatos afirmam que, em 1972, cerca de metade dos lotes atualmente existentes no MBV já estavam delimitados pelos próprios ocupantes, alguns especulando a sua valorização, como testemunha o sr. F. 0 relato anterior de d. DL confirma a condição de mobilidade entre a parte mais alta e a parte mais baixa, esta última mais valorizada pelo "mercado" de lotes no MBV.

Ainda no início da década de 1970, uma segunda torneira pública foi aberta, dessa vez no MBV, e a nascente mais utilizada foi cimentada de forma a evitar sua extinção e melhor servir aos moradores. A água encanada só viria em meados dessa década, aos poucos sendo distribuída pelas ruas. Relatos afirmam que, enquanto as casas não eram atendidas, a água gratuita era pouca e formavam-se filas para sua coleta, gerando, por vezes, um ambiente tenso entre os moradores. Todavia, os primeiros ocupantes relataram que as relações eram cordiais entre eles, ocorrendo mutirões, muitos destes destinados ao recapeamento do morro ou ao desmonte de rochas para a abertura de caminhos ou ruas, demolição promovida manualmente com o uso de ponteiros e martelos. Isso ocorria geralmente aos domingos, quando todos os habitantes estavam disponíveis. 0 testemunho do sr. J. B. evidencia essa alteração da geomorfologia local feita sem qualquer intervenção do poder público da época, colocando em risco a população local:

Nós já fizemos um recapeamento desse morro, nós mesmos, umas quinze vezes. Nós, com recursos nossos mesmos, brita, areia, cimento, mão de obra nossa mesmo. Matava gato... Quantos gatos nós matamos para fazer tira gosto! Pra botar na roda para todo mundo comer. Litros e litros e litros de cachaça pro povo beber. Pode perguntar pro pessoal. Tinha quem sempre dava uma cachaça e os meninos que matavam os gatos. A gente fazia aquela panelada de gato e danava a trabalhar. Então foi isso que foi criando essas ruas. Deixou de ser vielas e passou a ser ruas. 0 único lugar que tinha terra era ali assim. 0 resto era tudo pedregulho.

Segundo testemunhos, essa situação de cordialidade entre os habitantes começou a mudar no final dessa década de 1970 quando mais pessoas de origens e naturezas distintas começam a ocupar esse espaço. Parece ter sido, também, nesse momento que os primeiros burburinhos sobre o tráfico de entorpecentes se iniciaram.

Após o início da década de 1980, a pressão oriunda do déficit habitacional faz com que o processo de ocupação se dirigisse às áreas mais altas do MBV passíveis de ocupação. Novamente, esse processo ocorre sem um planejamento do espaço pelo poder público. Nessa década, os lotes na parte mais alta foram criados à medida que os novos moradores chegavam e apossavam-se da área. Essa ocupação favoreceu a alteração da geografia local, tornando-a uma área bastante antropizada com os anos, salvo onde a superfície do terreno possuía inclinação muito acentuada, dificultando a sua ocupação.

Em todo esse processo de ocupação e uso do solo, percebe-se a não participação do poder público nessa urbanização, característica dos aglomerados subnormais. Das características naturais desse ambiente, restam apenas as espécies vegetais epífitas presentes no paredão rochoso de difícil acesso, que se ergue e forma o pináculo, e os matacões de dimensões 
maiores poupados pelo desmonte feito pelos moradores, contribuindo para o quadro de instabilidade do local quanto a movimentos de massa. Sabe-se que as plantas influenciam, geralmente, na estabilização da superfície do substrato rochoso (Pinotti, 2010).

A partir do exposto, observa-se que a ideia de risco é uma construção social. 0 risco é alterado pelas transformações ocorridas no modo pelo qual uma comunidade usa e se apropria do solo. Vale lembrar que as comunidades podem desenvolver estratégias de resistência ou de resiliência espontâneas (pois sem intervenção do Estado), como os mutirões relatados acima. 0 risco é, assim, multidimensional, contendo variáveis social (política, cultural, cognitiva...) e biogeofísica do território. E essa multidimensionalidade pode ser trazida pela memória coletiva dos integrantes da comunidade que expressa a identidade coletiva no sentido de vir a constituir a história ambiental local (Halbwachs, 1950).

\section{Possibilidades e limites na RRD: Estado e subcidadania no cenário de uma "tragédia anunciada"}

0 evento ocorrido em janeiro de 2016 não foi algo inusitado. Afinal, a discussão acima aponta para a possibilidade da sua ocorrência. Vale lembrar o relatório do CPRM (2012), utilizado no Plano de Contingência de VV (2013), que falava claramente haver, no MBV, 16 áreas consideradas de alto ou muito alto risco, o que poderia até fundamentar a remoção imediata de moradores. Mesmo dois meses após o evento e com as obras de contenção sendo feitas, moradores apontavam a possibilidade de ocorrência de uma nova tragédia, tal como no relato dado à mídia local de uma moradora do MBV: "Ela [a pedra] tá solta. Ela já tá tombada lá em cima e tem outra empurrando ela para baixo. Eu vou esperar acontecer para falar que é uma fatalidade? Não tem como" (Falcão, 2016). 0 que estaria acontecendo, então, nesse cenário além dos fatos relatados anteriormente?

Pretende-se, nesta parte do texto, discutir os limites e as possibilidades da redução de risco de desastres (RRD) no viés da cidadania e do Estado. Nesse sentido, a construção histórica desse cenário é fundamental para se compreender o desastre de janeiro de 2016. Essa discussão se justifica por observações a partir das visitas in loco, realizadas posteriormente ao desastre, desvelando uma comunidade fragilizada pelo evento e, também, possivelmente, desarticulada para o enfrentamento do risco. Afinal, a comunidade parece não ter sido capaz de se articular para expor suas demandas cotidianas e nem para lidar com 0 risco de desastre, não reivindicando, do poder público, ações de gestão de RRD mesmo tendo o posicionamento do SGB e o rolamento de 2012, acima citados, como base para reivindicar a presença mais efetiva do Estado. A pouca capacidade de pressão popular pode apontar para lacunas deixadas pela falta de um projeto de RRD do poder público, voltado para o empoderamento dessa comunidade, em que o reconhecimento e o enfrentamento de situações de risco seriam mais bem-desenvolvidos através do acesso aos conhecimentos necessários para a compreensão desse cenário, contribuindo para a formação da cidadania. 
A falta de políticas públicas voltadas para a formação de cidadania tendo um recorte da RRD não é problema apenas do MBV. Segundo Souza (2006), essa sociedade desigual moderna teria sido capaz de contribuir para o processo de formação do que ele nomeia como sendo subcidadania, isto é, aqueles moradores com pouco ou sem qualquer acesso a conhecimentos e a reconhecimentos. Remetendo-se ao processo de modernização em grande escala do País, principalmente, na metade do século $X X$, de acordo com o autor, surgem setores "europeizados", aqueles inseridos nas demandas ou forças produtivas; e "...os setores 'não europeizados'", "precarizados", que tenderam, por seu abandono, a uma crescente e permanente marginalização" (ibid., p. 41). Assim, a lógica econômica do capitalismo no desenvolvimento brasileiro contribuiu ou contribui para a aumentar a situação de risco da população socialmente vulnerabilizadas.

Essa lógica não foi diferente no estado do $E S$, onde o desenvolvimento ocorre tardiamente se comparado a outras áreas do País (Siqueira, 2010; Mattos, 2011; Ribeiro et al., 2015). Lemos (2015, p. 194) resume bem o caso capixaba, para quem:

A expansão do capitalismo trouxe consigo seus reflexos, inerentes à própria lógica do capital de maximização dos lucros por meio do controle do mercado. A ampliação do capital depende da alta tecnologia combinada com a existência de mão de obra barata e matérias-primas com baixos custos. Dessa forma, o processo de concentração fundiária com a expulsão do homem do campo para a cidade contribuiu para a constituição de um desses fatores requeridos pelos capitalistas. Os retirantes passam a se constituir em mão de obra disponível e disposta a trabalhar por salários ínfimos por não encontrarem, em curto prazo, alternativa. Apesar da migração no sentido rural-rural que ocorreu no Espírito Santo em direção a Rondônia (ou a outras regiões da Amazônia) e que permaneceu ativa durante a década de 1990, a população capixaba teve um grande crescimento urbano [...]. A orientação principal dos migrantes caracteriza-se pelo sentido rural-urbano.

Esse é o caso do MBV: a expansão tardia de grandes projetos capitalistas atraindo migrantes de um campo em crise que se instalam num espaço urbano de suscetibilidade a perigos, como os movimentos de massa, por serem mão de obra barata disponível para ou receber salários indignos ou servir como moeda de barganha num clientelismo político que incita invasões ou se omite da responsabilidade da ocupação de áreas de baixo valor imobiliário, como é o caso das áreas de preservação permanente do município (Rolnik, 1999; Mattos, 2011; Sathler et al., 2016).

A comunidade do MBV é um caso do setor "não europeizados" (Souza, 2006), formado por populações marginalizadas pelo desenvolvimento ecologicamente insustentável e socialmente injusto, cujas vulnerabilidades são reveladas por eventos de diferentes naturezas, entre eles o desastre de janeiro de 2016. A ocupação do MBV deu-se nessas condições, nas quais os "subcidadãos" se tornam massa de manobra do clientelismo do poder político econômico (Rolnik, 1999; Sathler et al., 2016). No caso do MBV, as áreas foram ocupadas espontaneamente e com pouca participação do poder público ou com a sua anuência por conta da sua omissão. 
É nesse contexto de não reconhecimento dos direitos de cidadãos vulnerabilizados pelo processo de desenvolvimento capitalista industrial que se situaria uma política municipal de RRD, visando a construir uma cidadania para o enfrentamento do risco, aumentando a participação do poder público e a capacidade de publicização e de empoderamento da população. Se, no discurso, a Constituição Federal (CF) de 1988 estabelece entre os seus fundamentos a cidadania, o que se observa, na prática, é que essa cidadania ainda é uma lacuna no sentido de sua realização, como no caso do MBV. Ainda, a CF garante o direito a uma moradia digna, conforme o rol dos direitos sociais, apesar dos entraves das políticas habitacionais. Além disso, uma política pública de educação para cidadania, principalmente, para o reconhecimento dos seus direitos diante da RRD é uma demanda que vem sendo posta frequentemente no País.

Sendo assim, apesar de toda a dificuldade para a construção da cidadania, importa mencionar que o direito dispõe de instrumentos jurídicos capazes de mitigar a vulnerabilidade da população, assegurando alguns direitos em prol de uma vida digna. Inserem-se, dentre esses instrumentos, a ação popular, a ação civil pública e o mandado de segurança coletivo. Nota-se que, não obstante esses instrumentos estejam à sua disposição, em sua maioria, a população acaba por não os conhecer em vista de uma lacuna da educação voltada para o empoderamento e para a resiliência. Assim, por não ter uma liderança ativa e comprometida com a RRD, mostra-se, mais uma vez, apartada dos seus direitos. No caso do MBV, os moradores têm ao seu dispor órgãos de representação, tais como o Ministério Público e a Defensoria
Pública, que, utilizando dos instrumentos jurídicos, poderiam garantir de modo eficaz seus direitos. Nessa concepção, mais do que estabelecer de forma teórica esses direitos, faz-se necessário efetivá-los para que ultrapassem o plano do discurso, e isso através de Poder Público e da participação de líderes locais comprometidos com a comunidade.

Cabe ainda salientar que o Poder Público, diante dessas questões, deveria estar junto à comunidade, contribuindo para o enfrentamento do risco e não se omitindo. Tanto é assim que os próprios tribunais reconhecem a responsabilidade do Estado em suas diferentes esferas no que se refere aos deslizamentos quando caracterizada a sua omissão (Jusbrasil, 2018). Essa omissão evidencia a irresponsabilidade desse ator na gestão da RRD. Como ocorrido no MBV, esse ator não pode somente aparecer na fase da emergência ou do pós- desastre com obras estruturais nem tão pouco em casos de desocupação. Numa perspectiva de gestão de RRD, o Estado deve ser atuante em todas as suas etapas (mitigação, preparação, resposta e recuperação) e não somente ele, mas todos os atores inerentes a esse cenário (como, por exemplo, a comunidade, a academia e os órgãos não governamentais).

\section{Considerações finais}

Através dessa pesquisa, foi possível observar como a formação do tecido urbano da RMGV reproduziu os limites e as possibilidades do ocorrido nas demais metrópoles brasileiras. No caso do Morro da Boa Vista, fica clara a emergência do que a literatura considera como "subcidadãos", justamente como impacto 
do processo de desenvolvimento capitalista industrial moderno, injusto e insustentável. Desse modo e dentro do processo de uso e ocupação do solo urbano, essa categoria se vê apartada do restante da sociedade capixaba e brasileira, na medida em que é incluída no processo sociopoliticoeconômico "pela porta dos fundos". Nesse sentido, viram-se forçados a ocupar áreas de menor valor imobiliário, o que certamente está associado também ao risco geológico do local.

Mesmo após meio século de ocupação da urbe, os primeiros ocupantes do MBV não tiveram acesso a melhores condições de vida, tampouco tomaram ciência dos seus direitos. A Constituição Federal de 1988 veio, justamente, como um projeto de sociedade proporcionando um novo panorama para os subcidadãos, apresentando-Ihes uma nova perspectiva em termos de cidadania. Ocorre que, muito embora já se contam mais de 25 anos da sua promulgação, percebe-se que, para muitos, a eficácia desses direitos ainda parece estar distante, 0 que demonstra o desafio de que os Poderes constituídos pelo Estado, com base em um diálogo e cooperação mútua, engajem-se em prol desses subcidadãos.

Visto o descaso do poder público com situações como essa do MBV (que abundam pela nação na grave crise política e macroeconômica no momento presente), presume-se que, sem a comunhão dos integrantes dessa da comunidade e de sua organização em prol de seus direitos, especialmente em relação às áreas de risco, provavelmente, o objetivo de alcançarem o devido direito à cidadania ficará comprometido. Sem o esforço e a pressão conjunta da comunidade, a ação estatal não ocorrerá. Isto significa que há a necessidade da formação de lideranças locais capazes de publicizar as vulnerabilidades socioambientais e promover 0 "movimento" das instituições públicas correlacionadas. Nesse sentido, vale registrar que a comunidade estudada elegeu para a câmara dos vereadores, em 2016, uma liderança comunitária que se mobilizou na formação de uma comissão voltada para tratar da questão de risco e vulnerabilidade no município.

Afinal, o risco de desastre perdura e é iminente. Assume-se que, anterior a isso, é preciso que a comunidade compreenda o complexo processo que a coloca em situação de vulnerabilidade bem como os mecanismos que podem ser acionados a seu favor no sentido de se tornarem resilientes. Finalmente, este estudo faz emergir os vários fatores contribuintes para a vulnerabilização, sejam eles sociais, históricos, políticos, econômicos, geológicos e culturais da população, apontando, ainda, para omissões, não reconhecimentos, desconhecimentos de atores-chave dessa arena pública. 
[I] https://orcid.org/0000-0001-6613-5088

Universidade Vila Velha, Programa de Mestrado de Sociologia Política, Núcleo de Estudos Urbanos e Socioambientais. Vila Velha, ES/Brasil.

teresa.rosa@uvv.br

[II] https://orcid.org/0000-0002-8034-3155

Universidade Vila Velha, Programa de Mestrado em Sociologia Política, Núcleos de Estudos Urbanos e Socioambientais. Vila Velha, ES/Brasil.

marcelosathler.br@gmail.com

[III] https://orcid.org/0000-0003-4484-4275?

Universidade Vila Velha, Departamento de Geologia. Vila Velha, ES/Brasil.

mirian.costa@uvv.br

[IV] https://orcid.org/0000.0002.0708.9728

Universidade Federal do Rio de Janeiro, Escola Politécnica, Departamento de Construção Civil. Rio de Janeiro, RJ/Brasil.

mbm@poli.ufrj.br

[V] https://orcid.org/0000-0002-8032-6144

Universidade Estadual do Norte Fluminense Darcy Ribeiro, Laboratório de Estudo do Espaço Antrópico, Centro de Ciências do Homem. Campos dos Goytacazes, RJ/Brasil.

creginensi@gmail.com

[VI] https://orcid.org/0000-0001-5757-3617

Faculdades Multivix Cariacica, Curso de Direito. Multivix Vitória, Curso de Direito. Faculdade de Direito de Vitória, Grupo de Estudos, Pesquisa e Extensão em Políticas Públicas, Direito à Saúde e Bioética, Programa de Pós- Graduação em Direitos e Garantias Fundamentais. Vitória, ES/Brasil.

ricardomsouza83@gmail.com

\section{Notas}

(1) Ver na parte a seguir os registros históricos de dados pluviométricos.

(2) A descrição geológica detalhada é, hoje, alvo de estudos por esta equipe de pesquisadores. No entanto, tendo em vista as dificuldades de retorno ao local, em razão da falta de segurança e condições climáticas, esse tema será discutido em artigos científicos sobre a área em breve.

(3) O clima da área é classificado tropical do tipo Aw, de acordo com a Köppen e Geiger (2007), possuindo um verão mais úmido que o inverno; a temperatura média é de $24.7^{\circ} \mathrm{C}$ e a pluviosidade média anual é de $1117 \mathrm{~mm}$, que é considerada alta (Climate-Data.ORG, 2016). 
(4) Esse imposto é aplicável somente aos imóveis situados em ruas pavimentadas, o que reforça a informação dada anteriormente de que são poucas as ruas asfaltadas na área de estudo.

(5) O que significa que os imóveis desses entrevistados estão valorados em mais de $\mathrm{R} \$ 30$ mil.

(6) Razões do rolamento: Calor na pedra (27,78\%), Não sei $(22,22 \%)$, Bomba ou tiroteio $(16,67 \%)$, Causa natural $(11,11 \%)$, Ocupação do local $(5,55 \%)$, Deus $(5,55 \%)$, Excesso de peso $(5,55 \%)$, Desgaste do sol (5,55\%).

(7) Últimos, nesse testemunho, relaciona-se ao fato de eles estarem morando na parte mais alta do MBV.

(8) Aqui, essa fala se remete à área mais baixa do morro em contraposição à primeira moradia da sua família que se situava na parte mais alta.

(9) Tamancaria eram os locais onde se produziam tamancos de madeira.

(10) O cano mestre seria o encanamento principal da rede de abastecimento de água do bairro Cobi, bairro de Vila Velha vizinho a São Torquato e o MBV.

(11) Diferentemente de d. N., esse relato faz referência a uma nascente que seria de difícil acesso para os moradores locais por se situar próximo ao cume do MBV, em área mais íngreme.

(12) No caso, o recordador se refere a um milharal.

(13) O recordador menciona que andava horas na lavoura em busca de espigas de milho que não eram encontradas.

(14) Ferro e Aço era uma indústria local situada em VV.

(15) Formar a terra é um termo rural que significa realizar o plantio de lavoura ao ponto de iniciar a colheita.

\section{Referências}

AB'SABER, A. (2003). Os domínios de natureza no Brasil: potencialidades paisagísticas. São Paulo, Ateliê Editorial.

ALMEIDA, A. de (2010). Carlos Lindenberg: um estadista e seu tempo. Vitória, Apees.

ALMEIDA, J. L. de e GOMES, A. (1985). O processo de parcelamento do solo no distrito da Barra do Jucu. Trabalho de conclusão de curso. Vitória, Universidade Federal do Espírito Santo.

ASSUMPÇÃO, M.; BARBOSA, J. R.; BERROCAL, J.; BASSINI, A. M.; VELOSO, J. A. V.; MÂRZA, V. I.; HUELSEN, M. G. e RIBOTTA, L. C. (1997). Seismicity patterns and focal mechanisms in southeastern Brazil. Revista Brasileira de Geofísica. São Paulo, v. 15, n. 2, pp. 119-132.

BIG ALL (2016). Avaliação de Área de Risco no Morro do Boa Vista. Vitória. 
CATHARINO, E. L. M. (1989). Estudos fisinômicos-florísticos e fitossociológicos em matas residuais secundárias no município de Piracicaba, SP. Dissertação de Mestrado. Campinas, Universidade Estadual de Campinas.

CELANTE, S.; SATHLER, M. e da SILVA ROSA, T. (2015). Histórias de vida no resgate da história da ocupação do solo de Vila Velha (ES). In: XVII CONGRESSO BRASILEIRO DE SOCIOLOGIA. Anais. Porto Alegre, Sociedade Brasileira de Sociologia.

CEPED-UFSC (2013). Atlas Brasileiro de Desastres Naturais 1991 a 2012 (Volume Brasil). Florianópolis, Ceped-UFSC.

CLIMATE-DATA.ORG (2016). Clima: Vila Velha. Disponível em: <https://pt.climate-data.org/ location/3163/>. Acesso em: 19 dez 2016.

CPRM - Serviço Geológico do Brasil (2012). Ação emergencial para delimitação de áreas em alto e muito alto risco a enchentes e movimentos de massa: Vila Velha-Espírito Santo. Belo Horizonte, Ministério de Minas e Energia.

CPRM - Serviço Geológico do Brasil. Setoriação de Riscos Geológicos (2017). Disponível em: <http:// cprm.gov.br/publique/Gestao-Territorial/Geologia-de-Engenharia-e-Riscos-Geologicos/ Setorizacao-de-Riscos-Geologicos-4138.html>. Acesso em: 13 mar 2016.

DA SILVA ROSA, T.; SATHLER, M.; REGINENSI, C.; SEBASTIÃO, A. A.; MONTEIRO, T.; MENDONÇA, M. e CELANTE, S. (2016). Desastres e vulnerabilidade em contexto urbano moderno: o caso de Vila Velha (ES, Brasil) numa perspectiva socioambiental. In: CONGRESSO BRASILEIRO DE REDUÇÃO DE RISCOS DE DESASTRES. Anais. Curitiba, CEPED-UFSC, Universidade Positivo e Unespar.

DA SILVA ROSA, T.; MENDONÇA, M. B.; SEBASTIÃO JR, A. A.; SATHLER, M. A.; SOUZA, R. M.; MONTEIRO, T. G.; COSTA, M. C. O.; SIMPLICIO, M. A. R.; REGINENSI, C.; ANGELO, M. de e ANGELO, V. (2018). "Peripheral urban territories, disasters and extreme events: the case of the Morro do Boa Vista (Vila Velha, Espírito Santo, Brazil)". In: WALTER L. F. e FREITAS, L. E. de (orgs.). Climate Change Adaptation in Latin America: Managing Vulnerability, Fostering Resilience. Cham/Suíça, Springer International Publishing.

DEFESA CIVIL DE VILA VELHA (2013). Plano de contingência. Vila Velha, Prefeitura Municipal de Vila Velha.

DEFESA CIVIL ESTADUAL DO ES (2016). Laudo de vistoria de levantamento de risco. Vitória, Coordenadoria Estadual de Proteção e Defesa Civil do Espírito Santo.

DOUGLAS, M. e WILDAVSKY, A. (2012). Risco e cultura: um ensaio sobre a seleção de riscos tecnológicos e ambientais. Rio de Janeiro, Elsevier.

FALCÃO, A. (2016). Pedra volta a preocupar moradores do Morro da Boa Vista, no ES. Disponível em: <http://g1.globo.com/espirito-santo/noticia/2016/03/pedra-volta-preocupar-moradores-domorro-da-boa-vista-no-es.html>. Acesso em: 12 mar 2016.

JUSBRASIL (2018). Jurisprudência: deslizamento de terra e omissão. Disponível em: https://www. jusbrasil.com.br/jurisprudencia/busca?q=deslizamento+terra+omissão. Acesso em: 10 jan 2018.

GAMBOA, F. B. (2008). La construction sociale du risque: l'isthme de Tehuantepec face au phenômène climatique "El Niño" (Oaxaca, Méxique). Thèse de Doctorat. Paris, École des Hautes Études en Sciences Sociales.

GROTZINGER, J. e JORDAN, T. (2013). Para entender a Terra. Porto Alegre, Bookman. 
GUIDICINI, G. e NIEBLE, C. M. (1976). Estabilidade de taludes naturais e de escavação. São Paulo, Edgard Blücher.

HALBWACHS, M. (1950). La mémoire collective. Paris, Presses universitaires de France.

INCAPER - Instituto Capixaba de Pesquisa, Assistência Técnica e Extensão Rural (2017). Banco de Dados Agrometeorológico. Vitória.

LEMOS, M. A. (2015). “Modernização econômica e conflito social no Espírito Santo na década de 1980”. In: RIBEIRO, L. C. M.; QUINTÃO, L. do C.; FOLLADOR, K. J. e FERREIRA, G. L. (orgs.). Modernidade \& modernização. Vitória, Edufes.

LIMA, J. J. de C. (2002). Estudo da dilatação térmica de rochas usadas em revestimento de edificações. Dissertação de Mestrado. São Carlos, Universidade de São Paulo.

MALAMUD, B. D. e PETLEY, D. (2009). Lost in translation. Public service review: european science and technology. Leoben, Issue 2, pp. 164-167.

MARICATO, E. (1996). Metrópole na periferia do capitalismo: ilegalidade, desigualdade e violência. São Paulo, Hucitec.

MATTOS, R. (2011). Expansão urbana, segregação e violência: um estudo sobre a região metropolitana da Grande Vitória. Vitória, Edufes.

MENDONÇA, M. B.; DA SILVA ROSA, T.; GAVA, T. e SOUZA, R. M. (2015). Educação ambiental e cultura de resiliência: um estudo de caso em Niterói, brasil. In: SEMINÁRIO INTERNACIONAL DESNATURALIZAÇÃO DOS DESASTRES E MOBILIZAÇÃO COMUNITÁRIA: NOVO REGIME DE PRODUÇÃO DE SABER. Anais. Rio de Janeiro, Fiocruz.

MENDONÇA, M. B. e GULLO, F. T. (2017). "Percepção de risco associado a deslizamentos em Angra dos Reis, Rio de Janeiro, Brasil". In: MARCHEZINI, V.; WISNER, B.; LONDE, L. R. e SAITO, S. M. (org.). Reduction of vulnerability to disasters: from knowledge to action. São Carlos, RiMa Editora.

MONTEIRO, T. G. (2016). Do privado ao público em um contexto de injustiça ambiental: um estudo de duas comunidades às margens do Canal da Costa-Vila Velha (ES, Brasil). Dissertação de Mestrado. Vila Velha, Universidade Vila Velha.

OLIVEIRA, J. T. de. (2008). História do estado do Espírito Santo. Vitória, Apees.

PINOTTI, A. M. (2010). Técnicas de Geologia Estrutural para previsão e contenção de queda de blocos em encostas: aplicação na área do Granito Santos, Santos, SP. Trabalho de Conclusão de Curso. Campinas, Universidade Estadual de Campinas.

PORTO, M. F. DE S. (2007). Uma ecologia política dos riscos: princípios para integrarmos o local e o global na promoção da saúde e da justiça ambiental. Rio de Janeiro, Fiocruz.

REZENDE, R. (2016). Pedra gigante rola e atinge casas do Morro Boa Vista em Vila Velha. Disponível em: http://g1.globo.com/espirito-santo/noticia/2016/01/pedra-gigante-rola-e-atinge-casas-domorro-bela-vista-em-vila-velha.html. Acesso em: 12 mar 2016.

SAADI, A. (1993). Neotectônica da plataforma brasileira: esboço e interpretação preliminares. Geonomos. Belo Horizonte, v.1, n. 1, pp. 1-15.

SANTOS, J. (1999). Vila Velha: onde começou o estado do Espírito Santo: fragmentos de um história. Vila Velha. 
SATHLER, M.; DA SILVA ROSA, T.; AUGUSTO, A.; REGINENSI, C.; DE ANGELO, M.; SIMPlíCIO, A.; COSTA, M.; GAVA, T. e MENDONÇA, M. B. (2016). Vulnerability, Disasters and Urbanization in Peripheral Areas: the case of Vila Velha (ES, Brazil). In: IPSA WORLD CONGRESS OF POLITICAL SCIENCE, 24th. Poznán, Poland. Anais. Poznán, IPSA.

SILVA, I. V. da (2015). “A modernização do ES e a habitação popular nos anos 50: a formação de um conjunto habitacional”. In: RIBEIRO, L. C.; QUINTÃO, L. do C.; FOLLADOR, K. J. e FERREIRA, G. L. (orgs.). Modernidade e modernização no Espírito Santo. Vitória, Edufes.

SIQUEIRA, M. da P. S. (2001). Industrialização e empobrecimento urbano: o caso da Grande Vitória (1950-1980). Vitória, Edufes.

(2010). Industrialização e empobrecimento urbano: o caso da Grande Vitória. Vitória, Grafitusa.

SLOVIC, P. (1987). Perception of Risk. Science, v. 236, n. 4799, pp. 280-285.

SOUZA, J. (2006). A invisibilidade da desigualdade brasileira. Belo Horizonte, Editora UFMG.

UNISDR - United Nations International Strategy for Disaster reduction (2009). Terminology on disaster risk reduction. Geneva, UNISDR.

VALFRÉ, V. (2012). Simulação de desmoronamento de rochas em Vila Velha tem participação de 200 pessoas. Disponível em: <http://gazetaonline.globo.com/_conteudo/2012/11/noticias/ cidades/1376423-simulacao-de-desmoronamento-de-rochas-em-vila-velha-tem-participacaode-200-pessoas.html>. Acesso em: 15 jun 2017.

VEYRET, Y. e RICHEMOND, N. M. de (2007). “Definições e vulnerabilidades do risco”. In: VEYRET, Y. (org.). Os riscos: o homem como agressor e vítima do meio ambiente. São Paulo, Contexto.

VIEIRA, V. S. e MENEZES, R. G. (2015). Geologia e recursos minerais do estado do Espírito Santo: texto explicativo do mapa geológico e de recursos minerais. Belo Horizonte, CPRM.

Texto recebido em 18/fev/2018

Texto aprovado em 6/abr/2018 
